\title{
Impact of Using a Tobacco Heating System (THS) on Indoor Air Quality in a Nightclub
}

\author{
Violeta Kaunelienė*, Marija Meišutovič-Akhtarieva, Tadas Prasauskas, Darius Čiužas, \\ Edvinas Krugly, Karolina Keraitytė, Dainius Martuzevičius \\ Department of Environmental Technology, Faculty of Chemical Technology, Kaunas University of Technology, Kaunas \\ LT50254, Lithuania
}

\begin{abstract}
Heated tobacco products potentially reduces the risks of nicotine use. With most of the research on heated tobacco products (also known as "heat-not-burn" tobacco products) focusing on mainstream smoke, data on second-hand smoke has been limited to several chamber studies, and the effect on the indoor air quality in real-world settings has not yet been reported. Consequently, in this work, we assessed the pollution generated by a tobacco heating system (THS) in a hospitality venue. Volunteers used the THS in a nightclub during non-operating hours. Additionally, the indoor air quality of the club was evaluated during operating hours. The real-time aerosol particle concentration and the off-line carbonyl, nicotine and 3-ethenylpyridine concentrations were measured. The observed particle number concentrations were $1 \mathrm{E}+4$, $5 \mathrm{E}+4,1 \mathrm{E}+5$ and $1 \mathrm{E}+6$ to $1 \mathrm{E}+7 \mathrm{H} \mathrm{cm}^{-3}$ for the background, 10 users, 30 users and the club during operation, respectively, representing an increase by an order of magnitude for each subsequent scenario. The club featured relatively high background concentrations of gaseous pollutants, presumably due to third-hand smoke, and using the THS in the club during non-operating hours did not significantly affect the majority of these concentrations, with nicotine being an exception. Despite the increase in the background particle number and mass concentrations due to THS use, these values were still an order of magnitude lower than during operating hours.
\end{abstract}

Keywords: Indoor air quality; Heat not-burn; Environmental tobacco aerosol; Nicotine; Hospitality venue.

\section{INTRODUCTION}

Tobacco use is the leading cause of global preventable morbidity and mortality. In spite of much evidence on the adverse health effects of tobacco use, many people continue to smoke ( $\mathrm{Li}$ et al., 2018). Tobacco cigarette use is a highly addictive habit, making cessation a difficult and challenging task (Farsalinos et al., 2017). There is an increasing focus on developing harm reduction strategies to address the health risks of conventional cigarettes (CCs) (Lüdicke et al., 2018). Electronic cigarettes (ECs) are currently the most popular harm-reduction products, but many smokers do not find them sufficiently effective or satisfactory in fully substituting smoking (Farsalinos et al., 2017). Heating tobacco instead of burning can offer a potentially lower risk of delivering nicotine compared to CCs because it creates a less complex aerosol than burned tobacco (Jaccard et al., 2017). Moreover, research on heat-not-burn (HnB)

\footnotetext{
* Corresponding author.

Tel.: +370682 14778

E-mail address: violeta.kauneliene@ktu.lt
}

tobacco products (alternatively called "tobacco heating systems" [THSs] or novel tobacco products [NTBs]) has consistently demonstrated that harmful and potentially harmful constituents (HPHCs) are reduced or absent in the aerosols of heated tobacco. Simonavicius et al. (2018) reviewed thirty-one publications on $\mathrm{HnB}$ products and concluded that compared with $\mathrm{CCs}$, HnB products delivered up to $83 \%$ of nicotine and reduced levels of harmful and potentially harmful toxicants by at least $62 \%$ and particulate matter (PM) by at least $75 \%$. Most of studies however were related to the mainstream aerosol. The data on the second-hand $\mathrm{HnB}$ aerosol is yet limited to several studies (Mitova et al., 2016; Mottier et al., 2016; Protano et al., 2016; Ruprecht et al., 2017; Ichitsubo et al., 2018; MeišutovičAkhtarieva et al., 2019).

The concentrations of most investigated indoor air constituents during the use of $\mathrm{HnB}$ products in an environmentally controlled environment are similar to background levels (with the exception of aldehydes) and an order of magnitude lower than in the CC environmental aerosol (Mitova et al., 2016; Ruprecht et al., 2017; Ichitsubo et al., 2018; Meišutovič-Akhtarieva et al., 2019). The review by Kaunelienè et al. (2018) provided a comparative analysis of THS-generated pollution against general indoor 
air quality (IAQ) in various micro-environments, especially with combustion-based pollution sources present. The use of THS (as well as EC) in the controlled environment was found to result in the lowest concentrations of formaldehyde, benzene, toluene and $\mathrm{PM}_{2.5}$ (particles with aerodynamic diameter lower than $2.5 \mu \mathrm{m}$ ) among majority researched pollution sources $(\mathrm{CC}$, water-pipe, incense and mosquito coils). The exposure to significantly higher pollution levels of benzene, toluene and formaldehyde may occur in public environments, especially transport micro-environments.

Following the adoption of WHO Framework Tobacco Control Convention in 2003, smoking bans in public places have been introduced in many countries (WHO, 2017). A wide range of regulatory responses ranging from no regulation to complete bans were also applied to the harmreduction products (Etter et al., 2011). Bans against the use of nicotine-containing products in public spaces in many countries is possibly the main reason that the evidence on the passive exposure to the vapor released or exhaled from the harm-reduction products under real conditions is still scarce. Only four studies on the impact of EC to IAQ performed using human volunteers in natural settings were reported in a systematic review by Abidin et al. (2017).

The impact of HnB products on IAQ in real-life settings has not been investigated so far. The aim of this study was to simulate the variation of IAQ following the usage of $\mathrm{HnB}$ product (namely, THS) in a non-operating nightclub with varying amount of users, and compare it against the typical IAQ in a nightclub under operation.

\section{METHODS}

\section{Test Product}

Tobacco heating system THS 2.2 (further referred to as "IQOS") with HEETS Bronze Label fillings (Philip Morris International Inc., USA) were used.

\section{Premises}

The experiment was conducted in a nightclub in Kaunas, Lithuania, with the floor area of approx. $160 \mathrm{~m}^{2}$ and the volume of approx. $880 \mathrm{~m}^{3}$. The club premises may be subjectively divided into several areas, including wardrobe, bar area, DJ scene, the main dancing floor and seating areas (Fig. S1). The facility was equipped with a mechanical ventilation system, supplying the air via air handling unit equipped with rotary heat exchanger, $9100 \mathrm{~m}^{3} \mathrm{~h}^{-1}$ maximum airflow. However, this air handling unit was operated manually, while most of the time the club has been operated in the natural ventilation regime $(0.5 \mathrm{ACH}$ as determined by the $\mathrm{CO}_{2}$ concentration decay after the closure). The indoor of club was a non-smoking area following a smoking ban in public premises in Lithuania. The smoking room was located outdoors with the entrance from the main club area. During operation the club was attended by $200-400$ people at the time, while the smoking room may accommodate approx. 30 humans. No cooking activities took place in a club, only drinks and occasionally cold appetizers were served.

\section{Experimental Procedure}

The experiment was performed in February 2018 during the course of two campaigns. The first campaign (Campaign \#1) was carried out in non-working hours of the club to evaluate THS-generated pollution while avoiding presence of other active pollution sources over three days, each consisting of five measurement sessions: background, background with 10 humans present but without THS use, 10 humans simultaneously using THS, background with 30 humans present but without THS use and 30 humans using THS scattered all over the main club area. Each measurement session took 30 minutes. The experiments were conducted with only natural ventilation present (air handling unit off), since this reflects usual condition of a nightclub. After the both IQOS usage sessions, particle and $\mathrm{CO}_{2}$ concentration were reduced to the background levels via purging indoor air by running air handling unit at $75 \%$ capacity (equivalent to 7-8 ACH) for 30 minutes. Indoor air was sampled at the breathing height ( $1.5 \mathrm{~m}$ from the floor) at two locations, representing different type of occupancy: the main (dance floor) area of the club (Zone 1) and sitting area (Zone 2) (see Fig. S1). Zone 2 was located under an internal balcony thus restricted airflows around it, presumably decreasing the dispersion rate of the exhaled aerosol.

The second campaign was carried out for three days (Campaign \#2). During each day, 1 hour before the club opening (representing background) and 3 hours of club in operation were sampled in order to obtain the profile of IAQ occurring during typical club activities. During the third day, the real-time measurements were extended for 4 additional hours to obtain variation of pollutant concentrations until and after the closure of the club. Similar sampling locations were employed as in Campaign \#1. The ventilation during Campaign \#2 was adjusted manually running air handling unit at $25 \%$ capacity (equiv. of $2.6 \mathrm{ACH}$ ) with no attendees to $100 \%$ capacity (equiv. of $10 \mathrm{ACH}$ ) with the maximum attendees ( $\sim 00$ people).

\section{Analytics}

The real-time particle number concentration (PNC), $\mathrm{CO}_{2}$ concentration, relative humidity and temperature, as well as off-line carbonyls (acetaldehyde and formaldehyde), off-line nicotine and 3-ethenylpyridine concentration were analyzed.

The real-time size-segregated particle concentration have been measured using the Electrical Low Pressure Impactor (ELPI+; Dekati, Inc., Finland), at a flow rate of $10 \mathrm{~L} \mathrm{~min}^{-1}$. Real-time concentrations of aerosol samples have been registered in $1 \mathrm{~Hz}$ or $10 \mathrm{~Hz}$ intervals. The sampling airflow was being switched between Zone 1 and Zone 2 using a 3-way switching valve every 5 minutes. The sample was delivered to particle sampler using Tygon ${ }^{\circledR}$ formula E-3603 laboratory tubing. Such tubing has been confirmed as the best compromise considering particle losses (Asbach et al., 2016).

The values of carbon dioxide $\left(\mathrm{CO}_{2}\right)$, temperature, and relative humidity have been continuously recorded by air quality meters (IAQ-Calc 7545; TSI Inc., USA).

Concentration of nicotine and 3-ethenylpyridine (3-EP) has been estimated following the ISO 18145 procedure which 
is based on the collection of compounds by adsorption on a sorbent resin $(4.7 \times 70 \mathrm{~mm}$ in size, 2 sections, $40 / 80 \mathrm{mg}$ sorbent, 20/40 mesh; XAD ${ }^{\circledR}$; SKC Inc., USA), extraction and determination by gas chromatography-mass spectrometry (GC-MS; GCMS-QP2010 Ultra; Shimadzu Corp., Japan). Concentration of formaldehyde and acetaldehyde has been estimated following the ASTM D5197-03 procedure based on sample collection on a silica gel coated with 2,4dinitrophenylhydrazine (DNPH) reagent (SKC Inc.). The DNPH derivatives were analyzed for parent aldehydes utilizing high-performance liquid chromatography (HPLCDAD (UV)).

\section{Data Processing and Analysis}

The measured distributions were based on PNC (unit particles $\mathrm{cm}^{-3}$ or $\# \mathrm{~cm}^{-3}$ ). The particle size distribution (PSD) was based on the number density (concentration) distribution function, which represented particle concentration normalized to the particle size bin where it was measured, i.e., the number of particles per volume of air sized between $\mathrm{Dp}$ and $\mathrm{dDp}$. This is usually expressed mathematically as $\mathrm{Dp}=\mathrm{dN} / \mathrm{d} \operatorname{logDp}\left(\# \mathrm{~cm}^{-3}\right)$. The PSD data was adjusted for particle losses in the sampling lines due to diffusion and inertial/gravitational losses for each channel separately.

\section{RESULTS AND DISCUSSION}

\section{Time Resolved Variation of Aerosol Concentrations}

Highly time resolved aerosol concentration has been measured across the entire experiment, including both controlled usage of IQOS (Campaign \#1), as well as the uncontrolled operation of the club (Campaign \#2). The time series of PNC during the two measurement campaigns are shown in Fig. 1.
The controlled experiment (Campaign \#1) started with the background having the median particle concentration of $9.4 \mathrm{E}+3 \# \mathrm{~cm}^{-3}$ and $9.8 \mathrm{E}+3 \#^{-3} \mathrm{~cm}^{-3}$ in Zones 1 and 2 , respectively. This is a moderate concentration of particles observable in many general indoor living environments, usually ranging within $1 \mathrm{E}+3$ to $9 \mathrm{E}+4 \mathrm{H} \mathrm{cm}^{-3}$ (Fromme, 2012). This background was measured in the premises where no continuous activities were present after several days of workweek closure before the opening in the weekend. The entry of 10 volunteers did not affect the background concentration, with the median concentrations remaining at $9.2 \mathrm{E}+3 \#^{-3} \mathrm{~cm}^{-3}$ and $9.9 \mathrm{E}+3 \#^{-3} \mathrm{~cm}^{-3}$ in Zones 1 and 2, respectively. Moreover, no major variation of particle concentration has been registered. Human movement may have resulted in re-suspension of dust, but such supermicrometer particles were not reflected well in total particle concentration variation, possibly due to losses in the sampling line transport.

Once the 10 volunteers started using IQOS devices, the concentration of particles has increased, as reflected by the first peak (Fig. 1(a)). The maximum has been registered at $1.2 \mathrm{E}+5 \mathrm{\#} \mathrm{cm}^{-3}$, while the median concentrations were at $3.6 \mathrm{E}+4 \mathrm{C} \mathrm{cm}^{-3}$ and $3.5 \mathrm{E}+4 \mathrm{~cm}^{-3}$ in Zones 1 and 2 , respectively. This is a statistically significant increase $(\mathrm{p}<$ 0.05). Such level of particles is comparable to our simulation measurements in a room-scaled chamber with 1 volunteer and ventilation rate of 0.5 (Meišutovič-Akhtarieva et al., 2019). At the same time, this is relatively low-level compared to other hospitality environments even with smoking absent. In Germany very high median PNCs of

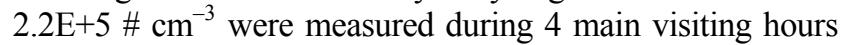
in non-smoking areas in four cafés/restaurants, $1.1 \mathrm{E}+5$ $\# \mathrm{~cm}^{-3}$ in two bars and $2.9 \mathrm{E}+5 \mathrm{~A} \mathrm{~cm}^{-3}$ in seven discos (Bolte et al., 2008).
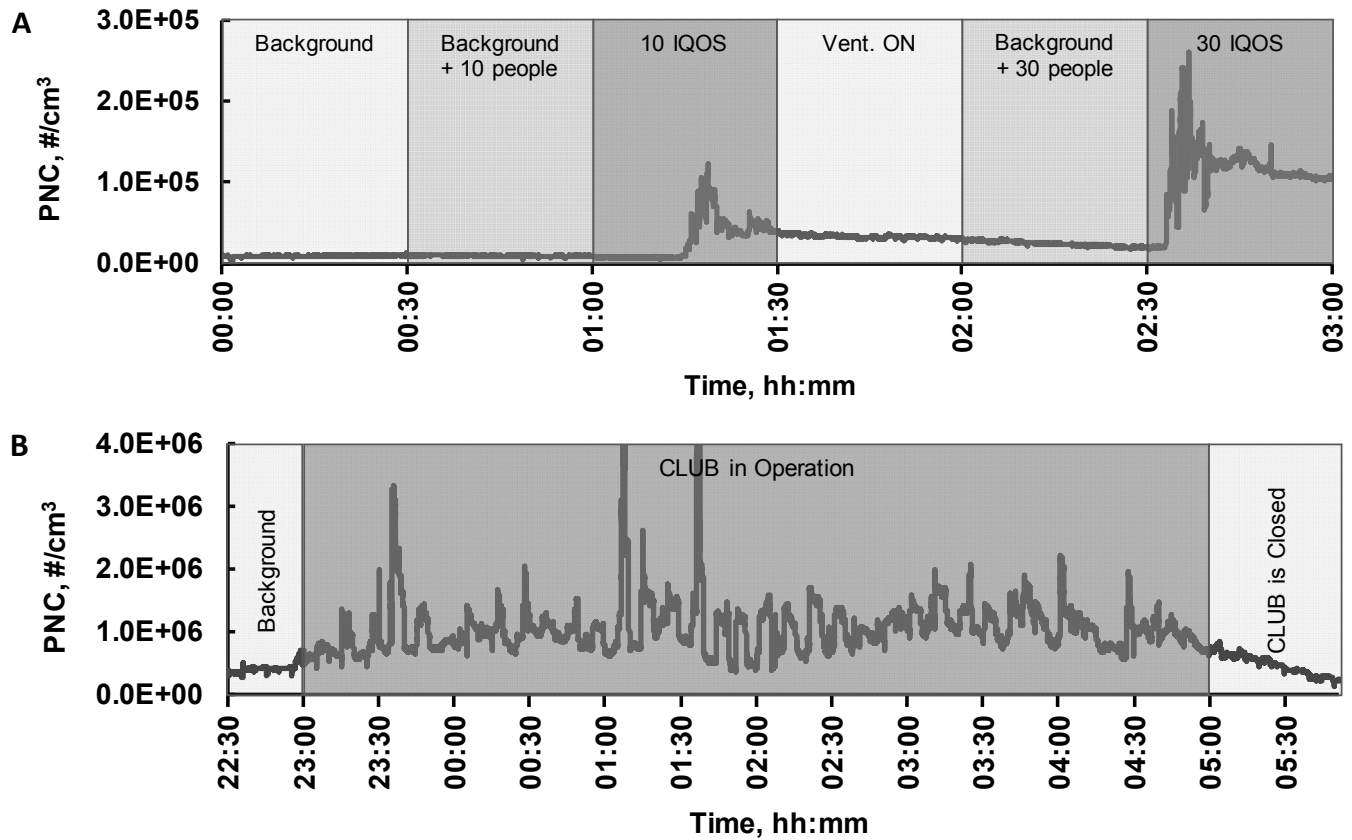

Fig. 1. Variations of PNC $\left(\# \mathrm{~cm}^{-3}\right)$ during controlled use of simultaneous 10 and 30 IQOS devices (above) and during uncontrolled operation of the club (below). 
Once usage of 10 IQOSs stopped, the concentration started decaying due to natural ventilation and further due to purging with forced ventilation to level of $4 \mathrm{E}+4 \mathrm{\#} \mathrm{cm}^{-3}$ $\left(\mathrm{CO}_{2}\right.$ level between $\left.460-480 \mathrm{ppm}\right)$, which served as a background concentration for 30 volunteers present in the premises.

Thirty IQOS users resulted in another significant increase of PNC to maximum value of $1.5 \mathrm{E}+5 \mathrm{\#} \mathrm{cm}^{-3}$, and median of $1.2 \mathrm{E}+5 \mathrm{\#} \mathrm{cm}^{-3}$ in Zone 1 and $1.3 \mathrm{E}+5 \#^{-3} \mathrm{~cm}^{-3}$ in Zone 2. Such levels are comparable to the one registered in a chamber with 5 volunteers using IQOS (Meišutovič-Akhtarieva et al., 2019) and in the higher range of hospitality environments such as German restaurants, pubs and discotheques, ranging from $1.2 \mathrm{E}+5 \mathrm{H} \mathrm{cm}^{-3}$ to $2.1 \mathrm{E}+5 \mathrm{\#} \mathrm{cm}^{-3}$ (Bolte et al., 2008). The concentration has not decreased quickly to the background. This did not agree with our findings from the simulations in a chamber, where we observed a rapid decay of concentrations to background levels, and attributed it to the short life span of volatile particles. Such difference from chamber findings is probably due to a much more intensive emission having 30 simultaneous users, as well as lower ventilation, having air handling unit off (air exchange rate approx. $0.5 \mathrm{ACH}$ ) during the test.

The preparations for the club opening (Campaign \#2) already resulted in high background values (of $2.7 \mathrm{E}+5$ \# $\mathrm{cm}^{-3}$ in Zone 1 and $2.9 \mathrm{E}+5 \mathrm{\#} \mathrm{cm}^{-3}$ in Zone 2; Fig. 1(b)). Yet the club operation resulted in the highest PNC (max.: 1.7E+7 $\# \mathrm{~cm}^{-3}$; median: $7.3 \mathrm{E}+5 \#^{\mathrm{cm}^{-3}}$ in Zone 1 and max.: $6.7 \mathrm{E}+6 \mathrm{H} \mathrm{cm}^{-3}$; median: $8.0 \mathrm{E}+5 \mathrm{\#} \mathrm{cm}^{-3}$ in Zone 2), which is statistically significantly higher compared to both backgrounds of the same day, but more importantly, all the scenarios involving IQOS usage. Such levels and variation is a result of the local particle sources, among most important were the operation of artificial fog machine as well as fugitive emissions from the adjacent smoking room, as confirmed further by the concentrations of CC markers. The particle levels were generally high, comparable to those registered in a chamber during the use of $\mathrm{CC}$
(Meišutovič-Akhtarieva et al., 2019), and higher than in German hospitality environments involving smoking of tobacco (Bolte et al., 2008).

A general trend comparing results of PNC increase from both measurement campaigns was as follows: background at $1 \mathrm{E}+4 \mathrm{~m} \mathrm{~cm}^{-3}, 10 \mathrm{IQOS}$ at $5 \mathrm{E}+4 \mathrm{H} \mathrm{cm}^{-3}, 30 \mathrm{IQOS}$ at $1 \mathrm{E}+5 \mathrm{H} \mathrm{cm}^{-3}$ and club in operation at $1 \mathrm{E}+6 \mathrm{~cm}^{-3}$ to $1 \mathrm{E}+7$ $\# \mathrm{~cm}^{-3}$. This represents an increase by an order of magnitude in each subsequent scenario.

\section{Particle Mass Concentrations}

The particle mass concentrations (PMCs) as calculated from real-time ELPI+ measurements were grouped based on the measurement scenarios (Fig. 2). Generally, $\mathrm{PM}_{2.5}$ and $\mathrm{PM}_{10}$ displayed similar variations between the measurement scenarios, except that $\mathrm{PM}_{10}$ indicated longer tails of distribution (represented by both $5^{\text {th }}$ and $95^{\text {th }}$ percentile whiskers), suggesting that there was higher variation of concentration. This is due to the fact that $\mathrm{PM}_{10}$ is more influenced by re-suspended dust, associated with human activities, while $\mathrm{PM}_{2.5}$ is associated with primary and secondary particles, resulting from thermal aerosol release (such as fog machines, cigarette smoking or exhalation of cigarette aerosol).

The scenarios from background to using 30 IQOS devices did not result in significant increase in PMC, with the median $\mathrm{PM}_{2.5}$ ranging from $2.7 \mu \mathrm{g} \mathrm{m}^{-3}$ at Zone 1 and $2.8 \mu \mathrm{g} \mathrm{m}^{-3}$ at Zone 2 in case of background to $11.4 \mu \mathrm{g} \mathrm{m}^{-3}$ (Zone 1) and $12.3 \mu \mathrm{g} \mathrm{m}^{-3}$ (Zone 2) in case of 30 IQOS. Such comparatively low impact of IQOS usage to indoor PMC may have resulted due to the fact that the majority of particles was located in sub-micrometer size range (as discussed in the following section), thus not carrying much mass. Another issue may be associated with the particle mass loss during the transport in sampling lines, since particles may have partially evaporated.

The operating club resulted in significantly higher concentrations compared to 30 IQOS users. Preparations to
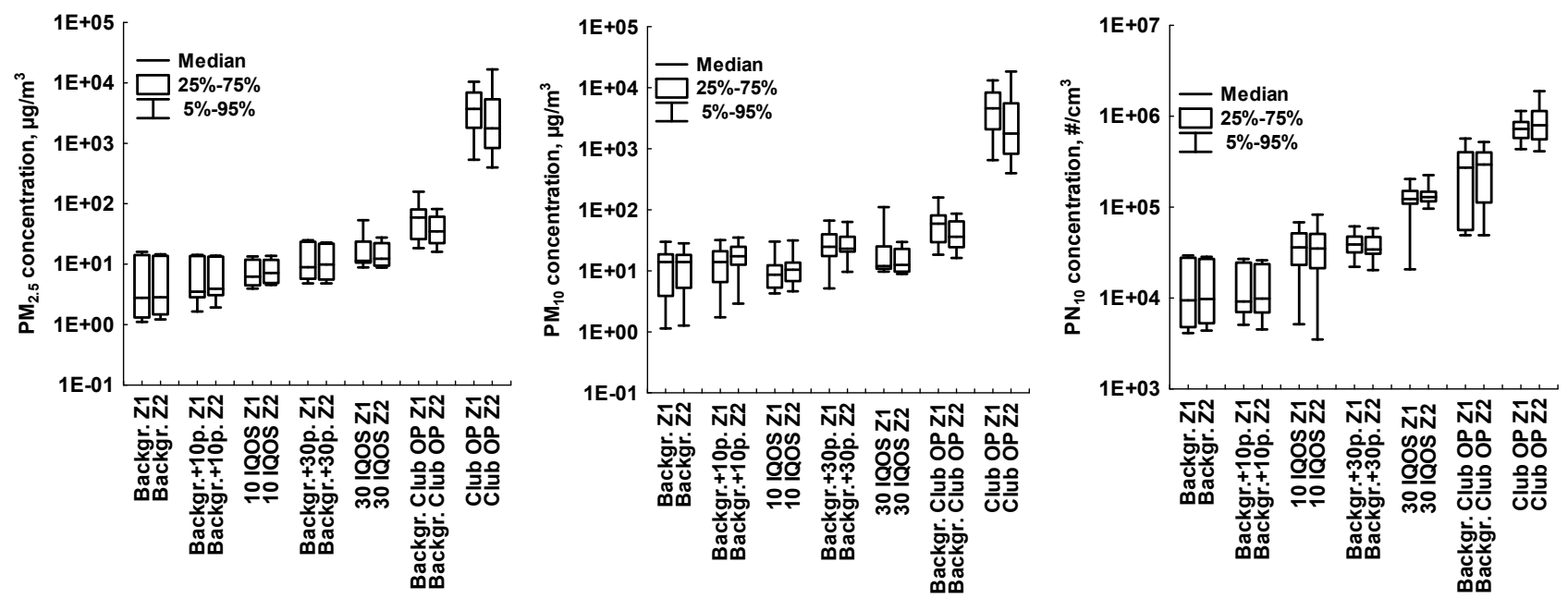

Fig. 2. Particle mass $\left(\mathrm{PM}_{2.5}\right.$ and $\left.\mathrm{PM}_{10}\right)$ and number $\left(\mathrm{PN}_{10}\right)$ concentrations in Zone 1 and Zone 2 under controlled conditions (10 IQOS and 30 IQOS) and club in operation (Club OP). Backgr. +10 p.: background with 10 humans present but without THS use; Backgr. +30 p.: background with 30 humans present but without THS use. 
the club opening already resulted in higher $\mathrm{PM}_{2.5}$ concentrations, this time having spatial variations between Zone $1\left(59.0 \mu \mathrm{g} \mathrm{m}^{-3}\right)$ and Zone $2\left(35.0 \mu \mathrm{g} \mathrm{m}^{-3}\right)$. This may be associated with more intensive staff moving and resuspending particles from surfaces, as well as potential secondary tobacco aerosol brought by staff from smoking room.

Further on, club in operation resulted in almost several orders of magnitude higher median $\mathrm{PM}_{2.5}\left(3715 \mu \mathrm{g} \mathrm{m}^{-3}\right.$ at Zone 1 and $1770 \mu \mathrm{g} \mathrm{m}^{-3}$ at Zone 2) and $\mathrm{PM}_{10}\left(4590 \mu \mathrm{g} \mathrm{m}^{-3}\right.$ at Zone 1 and $2470 \mu \mathrm{g} \mathrm{m}^{-3}$ at Zone 2) concentrations.

These levels are significantly higher than $\mathrm{PM}_{2.5}$ concentration in hospitality venues $\left(36-869 \mu \mathrm{g} \mathrm{m}^{-3}\right)$ as reviewed by Fromme et al. (2012) in smoking areas of Californian casinos during the periods of the highest occupancy (median: 44-110 $\mathrm{g} \mathrm{m} \mathrm{m}^{-3}$ ) (Klepeis et al., 2012) or German discotheques (median: $599.2 \mu \mathrm{g} \mathrm{m}^{-3}$ ) during the principal business hours before implementation of partial smoking ban (Gleich et al., 2011) and are closer to the mean $\mathrm{PM}_{2.5}$ and $\mathrm{PM}_{10}$ concentrations $\left(619.1 \mu \mathrm{g} \mathrm{m}^{-3}\right.$ and $1156.6 \mu \mathrm{g} \mathrm{m}^{-3}$ ) during rush working hours (17-21) at the combined water-pipe/CC smoking cafes in Tehran (Heydari et al., 2019). It must be noted that such differences in case of our measurements possibly result from the deriving of mass concentration from the real-time PNC measurements, as opposed to the filter-based collection. In the latter method, filters are conditioned before the gravimetric analysis, thus losing significant portion of the mass in case of volatile aerosol, which seems to be the case in our measurements, as indicated by the PSD analysis in the following section.

\section{Particle Size Distributions}

The PSDs based on PNC indicated that the major part of particles were of sub-micrometer size range, and more importantly, sub-100 nm range (Fig. 3(a)). It may be expected that aerosol in premises with thermal sources would have a mode at 80-100 $\mathrm{nm}$ range, indicating accumulating particles (Bolte et al., 2008). However, the ultrafine mode indicates that major portion of particles were at nucleation size range for all measurement scenarios. We have observed such phenomena in chamber for the exhaled THS aerosol and attributed such distribution to the rapidly evaporating volatile matter of the exhaled aerosol, which may reach $95 \%$ of total mass. Moreover, the measured RH levels during IQOS experiment averaged 36-43\%, which has been indicated as favorable range for the particle evaporation (Meišutovič-Akhtarieva et al., 2019). Club in operation yielded similar PSD, possibly reflecting the presence of highly volatile aerosol from fog machine, while RH stayed relatively low (29-35\%).

The PSD based on the mass concentration (Fig. 3(b)) indicated the mode at 200-300 nm during the use of IQOS and at $\sim 1 \mu \mathrm{m}$ during club in operation. The latter is associated with the fact that particle number concentration was significantly higher in that range, compared to IQOS. The PSD in the range of $2-10 \mu \mathrm{m}$ had much uncertainty associated with particle losses during sampling and thus could not be estimated quantitatively with high accuracy, but expectedly it should feature a mode in particle mass caused by the re-suspended dust from the moving personnel and visitors.

\section{Gaseous Pollutants}

The club featured relatively high background concentrations of gaseous pollutants (Fig. 4 and Table S1). The mean background concentration of formaldehyde (37.4 $\left.\mu \mathrm{g} \mathrm{m}^{-3}\right)$ and acetaldehyde $\left(41.1 \mu \mathrm{g} \mathrm{m}^{-3}\right)$ were higher than typically found in residential and public environments (Kauneliene et al., 2018). The mean background concentration of nicotine $\left(3.4 \mu \mathrm{g} \mathrm{m}^{-3}\right)$ and 3-EP $\left(1.7 \mu \mathrm{g} \mathrm{m}^{-3}\right)$ were similar to those measured in non-smoking areas of Finnish nightclubs and discos during peak hours (geometric mean: $2.9 \mu \mathrm{g} \mathrm{m}^{-3}$ and $0.8 \mu \mathrm{g} \mathrm{m}^{-3}$, respectively) (Johnsson
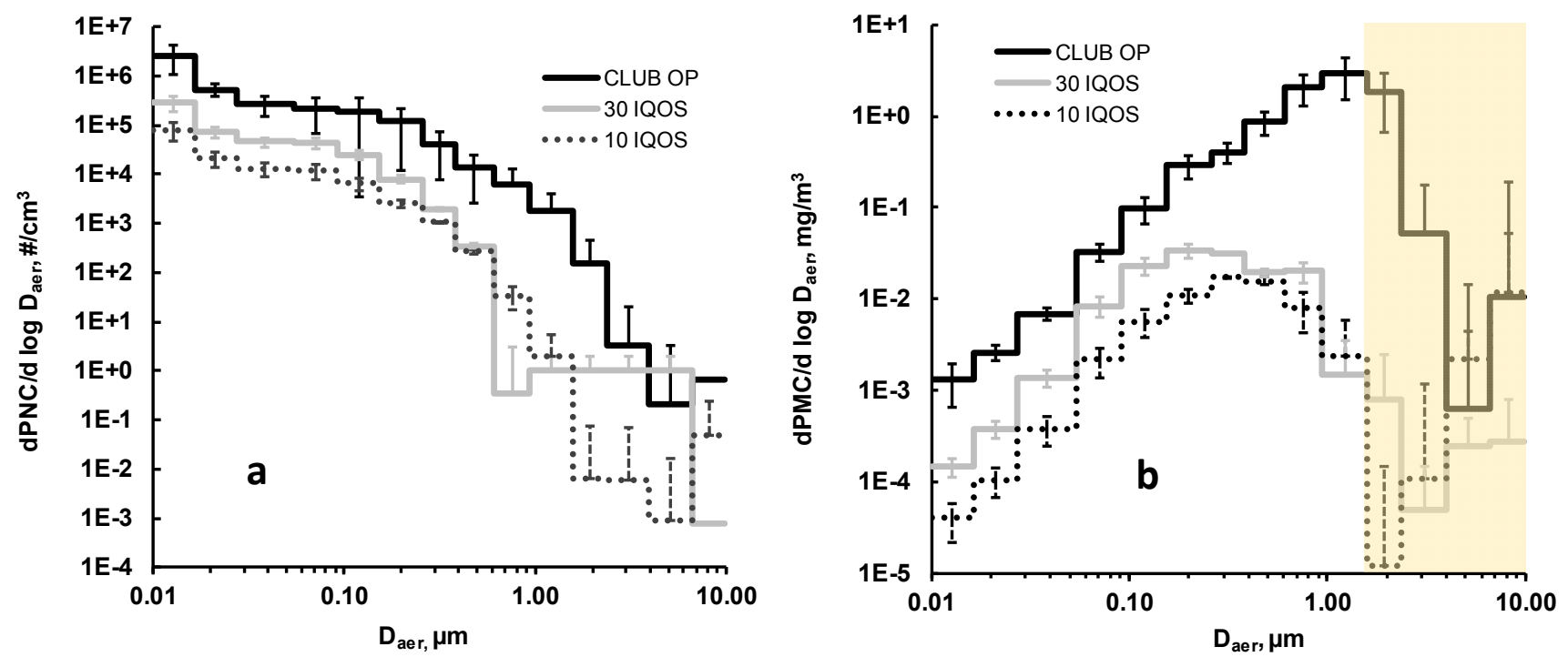

Fig. 3. Particle size distribution of (a) particle number concentration and (b) particle mass concentration during the use of THS under controlled conditions (10 IQOS and 30 IQOS) and club in operation. 

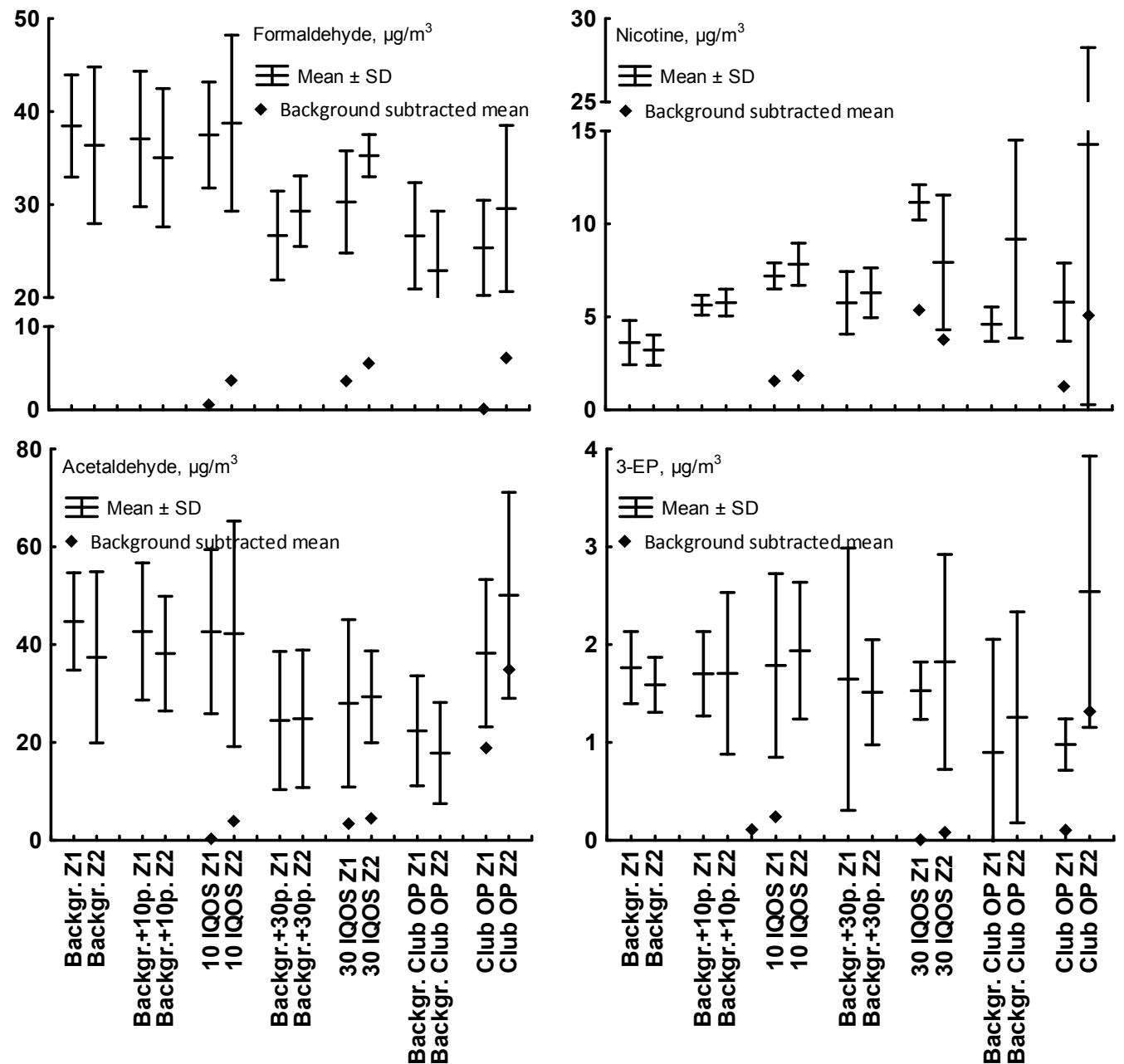

Fig. 4. Concentration of gaseous pollutants under different scenarios: 10 volunteers using IQOS (10 IQOS), 30 volunteers using IQOS (30 IQOS) and club in operation (CLUB OP). Z1: Zone 1; Z2: Zone 2. Background subtracted values are indicated as dots.

et al., 2006). Presumably, fugitive emissions from the smoking room as well as exhaled cigarette smoke and emissions from clothing and hair from returning smokers to the main club area resulted in substantial adsorption of tobacco combustion products and subsequent re-emission, so called third-hand smoke.

The impact of the usage of THS in non-operating club to the gaseous pollutant concentrations was much lower if at all significant compared to impact on particle concentrations (Fig. 4). The usage of 30 IQOS caused slight increase of concentrations as compared to 10 IQOS, however only increase of formaldehyde and acetaldehyde concentrations was statistically significant in Zone 1 ( $p<0.05)$. Hypothetically, the usage of IQOS in Zone 2 should have resulted in higher concentrations in comparison to Zone 1 due to restricted dispersion. This hypothesis has been partially confirmed for formaldehyde, acetaldehyde and nicotine (10 IQOS), but the differences did not appear to be statistically significant.

The club in operation resulted in either the similar levels of pollutants to 30 IQOS (formaldehyde and nicotine in Zone 2) or higher pollutant levels (3-EP and statistically significantly acetaldehyde). Although the club is a nonsmoking environment, Zone 2 was most likely affected by fugitive emissions of tobacco smoke from the adjacent smoking room. This is evidenced by increased concentrations of tobacco-specific markers - nicotine and 3-EP. Elevated levels of acetaldehyde may be attributed to the consumption of alcohol-containing beverages, as acetaldehyde is a product of ethanol metabolism and is present in the exhaled breath (Bagnardi et al., 2001).

The observed levels of nicotine during the use of 30 IQOS and club in operation were at same range compared to the concentrations in the smoking areas of Finnish nightclubs and discos during peak hours (geometric mean: $11.0 \mu \mathrm{g} \mathrm{m}^{-3}$ and $2.4 \mu \mathrm{g} \mathrm{m}^{-3}$, respectively; Johnsson et al., 2006), Las Vegas casinos where smoking is still not banned $\left(6.7 \mu \mathrm{g} \mathrm{m}^{-3}\right.$; Achutan et al., 2011) and New York City hookah bars during hours of the highest occupancy $\left(4.2 \mu \mathrm{g} \mathrm{m}^{-3}\right.$; Zhou et al., 2015).

Penetration of pollutants from smoking areas to nonsmoking areas has been reported in multiple earlier research campaigns. South Australian pubs, clubs and cafes having separately enclosed smoking areas had lower 
mean levels of nicotine $\left(4.4 \mu \mathrm{g} \mathrm{m}^{-3}\right)$ compared to the unenclosed ones $\left(7.5 \mu \mathrm{g} \mathrm{m}^{-3}\right)$, while air of smoking areas contained nicotine concentration of $15 \mu \mathrm{g} \mathrm{m} \mathrm{m}^{-3}$ measured over a period of 2-4 hours during a normal to busy dinner or lunch sessions (Cenko et al., 2004). Pollutant concentrations were significantly higher in Spanish hospitality venues with outdoor smokers close to the entrance than in those without outdoor smokers measured during the same range of hours (morning/afternoon) (López et al., 2013).

\section{CONCLUSIONS}

The usage of THS use in the nightclub increased the background particle number and mass concentrations by an order of magnitude, but these values nevertheless remained an order of magnitude lower than those measured during the club's operating hours, which were also influenced by fugitive emissions from the adjacent smoking room and the fogging machines. Particles generated by both the THS and the club in operation exhibited high volatility, as indicated by the sizable nucleation-mode fraction of the particle distribution. However, the THS did not significantly affect the majority of the gaseous pollutant concentrations in the club, which displayed high background values for tobacco-smoke-related pollutants.

Although intensive THS use (e.g., 30 simultaneous users) in indoor hospitality environments may be associated with deteriorating air quality and increased exposure to nicotine and acetaldehyde as well as particles, traditional cigarettes, despite the partial smoking ban, potentially remain the largest factor in the exposure of guests.

\section{ACKNOWLEDGMENTS}

Staff of the nightclub Mojo Lounge in Kaunas is acknowledged for the possibility to perform the experiment. Ms. Lauryna Dabašinskaite is acknowledged for the technical assistance during experiments.

\section{DISCLAIMER}

This research was funded by an Investigator-Initiated Study award by Philip Morris Products SA (IIS.PMI.2017.16). The study protocol was written by the investigator, who also conducted the study. Philip Morris Products SA had no involvement in the study conduct, data analysis and writing of the manuscript.

\section{SUPPLEMENTARY MATERIAL}

Supplementary data associated with this article can be found in the online version at http://www.aaqr.org.

\section{REFERENCES}

Asbach, C., Kaminski, H., Lamboy, Y., Schneiderwind, U., Fierz, M. and Todea, A.M. (2016). Silicone sampling tubes can cause drastic artifacts in measurements with aerosol instrumentation based on unipolar diffusion charging Silicone sampling tubes can cause drastic artifacts in measurements with aerosol instrumentation based on unipolar diffusion charging. Aerosol Sci. Technol. 50: 1375-1384.

Bagnardi, V., Blangiardo, M., La Vecchia, C. and Corrao, G. (2001). Alcohol consumption and the risk of cancer: A meta-analysis. Alcohol Res. Health 25: 263-270.

Bolte, G., Heitmann, D., Kiranoglu, M., Schierl, R., Diemer, J., Koerner, W. and Fromme, H. (2008). Exposure to environmental tobacco smoke in German restaurants, pubs and discotheques. J. Exposure Sci. Environ. Epidemiol. 18: 262-271.

Cenko, C., Pisaniello, D. and Esterman, A. (2004). A study of environmental tobacco smoke in South Australian pubs, clubs and cafes. Int. J. Environ. Health Res. 14: 311.

Etter, J.F., Bullen, C., Flouris, A.D., Laugesen, M. and Eissenberg, T. (2011). Electronic nicotine delivery systems: A research agenda. Tobacco Control 20: 243248.

Farsalinos, K.E., Yannovits, N., Sarri, T., Voudris, V. and Poulas, K. (2017). Nicotine delivery to the aerosol of a heat-not-burn tobacco product: Comparison with a tobacco cigarette and e-cigarettes. Nicotine Tob. Res. 20: 1004-1009.

Fromme, H. (2012). Particles in the indoor environment. In Air Quality - Monitoring and Modeling. Kumar, S. and Kumar, R. (Eds.), InTech, Croatia, pp. 117-144.

Gleich, F., Mons, U. and Pötschke-Langer, M. (2011). Air contamination due to smoking in German restaurants, bars, and other venues--before and after the implementation of a partial smoking ban. Nicotine Tob. Res. 13: 11551160.

Heydari, G., Taghizdeh, F., Fazlzadeh, M., Jafari, A.J., Asadgol, Z., Mehrizi, E.A., Moradi, M. and Arfaeinia, H. (2019). Levels and health risk assessments of particulate matters $\left(\mathrm{PM}_{2.5}\right.$ and $\left.\mathrm{PM}_{10}\right)$ in indoor/outdoor air of waterpipe cafés in Tehran, Iran. 26: 7205-7215.

Ichitsubo, H. and Kotaki, M. (2018). Indoor air quality (IAQ) evaluation of a Novel Tobacco Vapor (NTV) product. Regul. Toxicol. Pharm. 92: 278-294.

Jaccard, G., Tafin Djoko, D., Moennikes, O., Jeannet, C., Kondylis, A. and Belushkin, M. (2017). Comparative assessment of HPHC yields in the Tobacco Heating System THS2.2 and commercial cigarettes. Regul. Toxicol. Pharm. 90: 1-8.

Johnsson, T., Tuomi, T., Riuttala, H., Hyvärinen, M., Rothberg, M. and Reijula, K. (2006). Environmental tobacco smoke in finnish restaurants and bars before and after smoking restrictions were introduced. Ann. Occup. Hyg. 50: 331-341.

Kaunelienè, V., Meišutovič-Akhtarieva, M. and Martuzevičius, D. (2018). A review of the impacts of tobacco heating system on indoor air quality versus conventional pollution sources. Chemosphere 206: 568578.

Klepeis, N.E., Omoto, J., Ong, S L., Omoto, H.S. and Dhaliwal, N. (2012). Small proportions of activelysmoking patrons and high $\mathrm{PM}_{2.5}$ levels in southern 
California tribal casinos: Support for smoking bans or designated smoking areas. BMC Pub. Health 12: 819.

Li, X., Luo, Y., Jiang, X., Zhang, H., Zhu, F., Hu, S., Hou, H., Hu, Q. and Pang, Y. (2018). Chemical analysis and simulated pyrolysis of Tobacco Heating System 2.2 compared to conventional cigarettes. Nicotine Tob. Res. 21: 111-118.

López, M.J., Fernández, E., Pérez-Rios, M., MartínezSánchez, J.M., Schiaffino, A., Galán, I., Moncada, A., Fu, M., Montes, A., Saltó, E. and Nebot, M. (2012). Impact of the 2011 spanish smoking ban in hospitality venues: Indoor secondhand smoke exposure and influence of outdoor smoking. Nicotine Tob. Res. 15: 992-996.

Lüdicke, F., Picavet, P., Baker, G., Haziza, C., Poux, V., Lama, N. and Weitkunat, R. (2018). Effects of switching to the Tobacco Heating System 2.2 menthol, smoking abstinence, or continued cigarette smoking on biomarkers of exposure: A randomized, controlled, open-label, multicenter study in sequential confinement and ambulatory settings (Part 1). Nicotine Tob. Res. 20: 161-172.

Meišutovič-Akhtarieva, M., Prasauskas, T., Čiužas, D., Krugly, E., Keraitytė, K., Martuzevičius, D. and Kauneliené, V. (2019). Impacts of exhaled aerosol from the usage of the tobacco heating system to indoor air quality: A chamber study. Chemosphere 223: 474-482.

Mitova, M.I., Campelos, P.B., Goujon-Ginglinger, C.G., Maeder, S., Mottier, N., Rouget, E.G.R., Tharin, M. and Tricker, A.R. (2016). Comparison of the impact of the Tobacco Heating System 2.2 and a cigarette on indoor air quality. Regul. Toxicol. Pharm. 80: 91-101.

Mottier, N., Tharin, M., Cluse, C., Crudo, J.-R., Lueso, M.G., Goujon-Ginglinger, C.G., Jaquier, A., Mitova, M.I., Rouget, E.G.R., Schaller, M. and Solioz, J. (2016). Validation of selected analytical methods using accuracy profiles to assess the impact of a Tobacco Heating System on indoor air quality. Talanta 158: 165-178.

Ruprecht, A.A., De Marco, C., Saffari, A., Pozzi, P., Mazza, R., Veronese, C., Angellotti, G., Munarini, E., Ogliari, A.C., Westerdahl, D., Hasheminassab, S., Shafer, M.M., Schauer, J.J., Repace, J., Sioutas, C. and Boffi, R. (2017). Environmental pollution and emission factors of electronic cigarettes, heat-not-burn tobacco products, and conventional cigarettes. Aerosol Sci. Technol. 51: 674-684.

Simonavicius, E., Mcneill, A., Shahab, L. and Brose, L.S. (2019). Heat-not-burn tobacco products: A systematic literature review. Tob. Control 28: 582-594.

WHO (2017). Monitoring tobacco use and prevention policies, World Health Organization. http://apps.who.int /bookorders.

Zhou, S., Weitzman, M., Vilcassim, R., Wilson, J., Legrand, N., Saunders, E., Travers, M., Chen, L.C., Peltier, R. and Gordon, T. (2015). Air quality in New York City hookah bars. Tob. Control 24: e193-e198.

Received for review, April 18, 2019 Revised, June 30, 2019 Accepted, July 6, 2019 